\title{
GÉNESIS DE LOS TEJIDOS TURÍSTICOS MADUROS. El proceso de transformación de la forma urbana de Palmanova-Torrenova de Calviá, Mallorca
}

Biel HORRACH ESTARELLAS

Desde el nacimiento del turismo de masas en la década de 1950, muchos destinos del litoral europeo han tendido a experimentar un acelerado proceso de degradación. Primero fueron algunos de los destinos de primera generación, ubicados en el litoral Atlántico europeo, que en los años 70' ya presentaban claros síntomas de estancamiento y declive (Butler, 1980). Posteriormente, este fenómeno se traslada a los principales espacios turísticos del Mediterráneo, convirtiéndose en las últimas tres décadas en uno de los grandes retos a afrontar. Mediante el presente artículo, a partir del análisis del espacio central de uno de los principales destinos de la isla de Mallorca, Palmanova-Torrenova, se pretende comprender el origen y los procesos experimentados por este tejido turístico que en la actualidad se encuentra en fase de estancamiento.

Mallorca, turismo litoral, tejido maduro, ciclo de vida

\section{GENESIS OF MATURE TOURIST DESTINATIONS. The transfor- mation process of Palmanova- Torrenova de Calvià urban form, Mallorca}

Since the birth of mass tourism in the 1950s, many European coastal destinations have tended to experience an accelerated degradation process. Initially, it happened to some of the first generation destinations, located in the European Atlantic coast, which in the 70', showed clear signs of stagnation and decline. Afterwards, this phenomenon moved to the main tourist areas of the Mediterranean, becoming an important challenge to face during the last three decades. Throughout this paper, which is based on the analysis of one of the main tourist destinations central area of Mallorca island, Palmanova-Torrenova, is intended to understand the origin and the processes experienced by this tourist fabrics which currently are in phase of stagnation.

Mallorca, coastal tourism, mature fabric, lifecycle 
Desde inicios de los años 90 se ha podido observar cómo muchos de los espacios turísticos tradicionales del litoral del Mediterráneo Europeo se han convertido en destinos maduros. Este fenómeno, que ya fue experimentado por los destinos de primera generación del sur de Inglaterra (Knowles y Curtis, 1999), es estudiado desde el campo de la geografía mediante los ciclos de vida de los destinos turísticos, definiéndose 6 fases (Butler, 1980): exploración, implicación, desarrollo, consolidación, estancamiento y declive. Los destinos maduros se encontrarían en las fases de estancamiento o declive.

"La fase de madurez se explica principalmente por la saturación de la demanda del producto tradicionalmente ofertado, bajo grado de diferenciación de los productos, aparición de destinos sustitutivos, infraestructuras obsoletas y una masificación del espacio con un consiguiente desgaste del medio. En las circunstancias descritas, la calidad percibida del destino por el turista se ve deteriorada, lo que conlleva una reducción de la capacidad de atraer nuevos turistas" (González, 2010).

El objeto de este artículo es analizar el proceso de transformación por el cual los tejidos turísticos del litoral de Mallorca han devenido maduros, no solo como consecuencia de la evolución del mercado turístico internacional, tratado en numerosas investigaciones, sino también, mediante las transformaciones de su propia forma urbana y de los cambios de uso.

Como punto de partida, esta investigación trata de romper con dos tópicos habituales sobre los tejidos turísticos maduros en situación crítica. Por un lado en diferentes estudios se ha afirmado que los espacios turísticos maduros del Mediterráneo son fruto de desarrollos espontáneos debidos a la falta de planificación del litoral (Kowles y Curtis, 1999; Socías, 2001; Ruzza, 2003; Moreno, 2010). Sin embargo, constataremos que se trata de tejidos turísticos planificados según los cánones del momento, llegándose a convertir en espacios de referencia a nivel internacional. Por otro lado, veremos que estos tejidos no son fruto de la etapa del turismo de masas, sino que su origen se remonta a la etapa anterior a la Guerra Civil. Y es que en este segundo punto se basa la consolidación de Mallorca como uno de los principales destinos mundiales de sol y playa, ya que durante el inicio del fenómeno del turismo de masas la Isla dispone de unos desarrollos incipientes de características paisajísticas suficientemente atractivas, en un momento en 
que las administraciones públicas no disponían de capital para invertir en este campo; a éste factor hay que añadir el efecto que produce el imaginario colectivo creado sobre el lugar, lo que genera una notable atracción.

Para analizar el proceso de génesis y transformación de un tejido turístico, hasta convertirse en maduro, se ha seguido el siguiente método:

- Reconocimiento de la estructura base que origina el tejido, mediante el estudio de las lógicas de ubicación, de ordenación y la tipología inicial.

- Estudio de la evolución de los instrumentos de planeamiento que lo han ordenado y regulado en las distintas etapas.

- Decodificación del resultado de la forma urbana actual y de los cambios de uso, producto del proceso de transformación.

\section{Los tejidos maduros de Mallorca}

Podemos afirmar que la actividad turística busca en un principio generar espacios suficientemente atractivos para poder satisfacer las expectativas del imaginario del turista. Los ámbitos desarrollados con este fin, constituyen en general espacios turísticos cuya integración paisajística permite en un principio conformar un destino competitivo, desde el punto de vista espacial, a largo plazo.

Si bien los espacios conformados antes del boom del turismo de masas suelen presentar una ordenación armónica con el paisaje del conjunto, la alteración de su morfología para dar respuesta a una demanda creciente es la causa principal de su degradación, que les lleva a las etapas finales de su ciclo de vida.

El litoral de Mallorca alberga un importante número de espacios turísticos y vacacionales anteriores al inicio del turismo de masas. Los principales tejidos turísticos desarrollados en este periodo son los asentamientos suburbanos, las mallas, las ciudades jardín y los centros autónomos (Horrach, 2008).

Respecto a las lógicas de ubicación, estos destinos buscan especialmente dos tipos de paisajes litorales: grandes playas, o conjuntos de calas. Las grandes playas se encuentran esencialmente en las bahías de Palma y Alcudia, donde se proyectan desarrollos de ciudad jardín con extensiones entre 200 y 300 hectáreas. En cambio, en torno a los sistemas de calas se establecen ciudades jardín de dimensiones que oscilan entre las 10 y 50 ha, como el caso de Palmanova, Cala d'Or, Peguera, o Cala Major. La excepción es Santa Ponça, en donde se proyecta una nueva ciudad turística con una extensión superior a las 900 ha.

Previo a estos proyectos encontramos núcleos vacacionales, en forma de asentamientos suburbanos y colonias en malla (Horrach, 2008), frecuentados 
especialmente por residentes, fruto de los crecimientos suburbanos vinculados a explotaciones de pesca o canteras, o de la conformación de las colonias agrícolas o pesqueras en malla, que desde finales del siglo XIX se convierten en núcleos vacacionales.

Con la llegada del turismo de masas desde finales de los años 50', los tejidos turísticos más antiguos son los que experimentan un mayor desarrollo, transformando su morfología original, para adaptarse a la nueva demanda de alojamiento del turismo de masas. Es así como en 1965 la bahía de Palma concentra la mayoría de los destinos de la isla con más de 1.500 plazas hoteleras (González, 2010): “... cinco pertenecientes al municipio de Palma (s'Arenal, Platja de Palma, Can Pastilla, El Terreno-Porto Pi y Cala MajorSant Agustí), dos en Calvià (Peguera-Cala Fornells y Palmanova), uno en Llucmajor (s'Arenal) y otro en Sóller (Port de Sóller). Con 36.837 plazas hoteleras, la bahía de Palma, desde Magaluf (Calvià) hasta s'Arenal de Llucmajor, concentraba el 63,94\% de las plazas de la isla en 1965 ”.

Observamos como todos los destinos que experimentan un importante crecimiento durante la primera etapa del turismo de masas (1959-1965), son tejidos originados con anterioridad a este fenómeno. La mayoría de ellos son considerados hoy en día destinos maduros, especialmente aquellos que presentan mejores comunicaciones, primero con el puerto y posteriormente con el aeropuerto.

Si los destinos maduros se encuentran en fase de declive y estancamiento (Butler, 1980), en la fase de declive identificamos aquellos destinos que no son capaces de ofrecer un producto que se adapte a los cambios de motivación que ha experimentado el turismo, como sería el caso de s'Arenal de Llucmajor, el Terreno o Cala Major; mientras que entre los estancados detectamos aquellos que después de haber experimentado diferentes fases de desarrollo acaban especializándose en un único producto que va reduciendo la diversidad del perfil del turista, expulsando los segmentos más cualificados. Entre los principales destinos "estancados", analizaremos el de PalmanovaTorrenova, que por su rápido crecimiento se convierte en uno de los lugares representativos de la "Balearización".

\section{El caso de Palmanova-Torrenova}

Palmanova-Torrenova forman parte del Sistema Turístico-Litoral de Magaluf que va de Son Caliu a Portals Vells, abarcando un continuo urbano de más de 7,5 kilómetros. Actualmente cuenta con un total de 13.216 residentes, 29.941 plazas hoteleras y 14.614 plazas del resto tipologías turísticas ${ }^{2}$. Se trata

1 Según Enciclopedia de Mallorca en Vol. 12 pp. 319.

2 Según Memoria de la Adaptación del PGOU de Calvià al Plan Territorial de Mallorca (2009). 


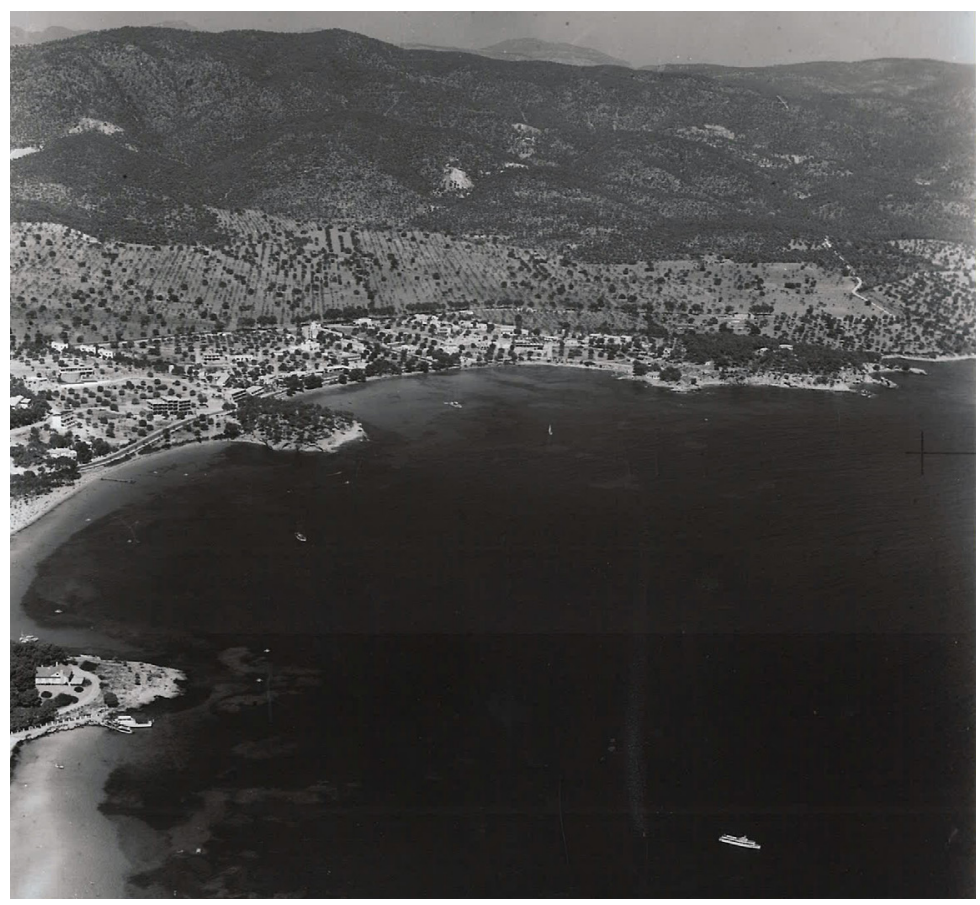

Fig. 1: Vista aérea de Palmanova en 1960. Fuente: archivo municipal de Calvià.

del principal destino del municipio con más plazas turísticas de Mallorca, Calvià, ubicado en el sector de poniente de la bahía de Palma.

\subsection{Origen de la ciudad jardín}

Si desde el campo de la geografía del turismo se afirma que buena parte de los atractivos turísticos de la isla ya fueron dados a conocer por los viajeros del siglo XIX (Seguí Llinàs, 1992), el municipio de Calvià, a pesar de llegar a ser en la actualidad el municipio más turístico de la isla, hasta mediados de los años 30, apenas aparece como un lugar destacado en las guías de viaje.

Y es que no es hasta el año 1925 que, con a llegada de nuevos cruceros, tras las mejoras realizadas en el Puerto de Palma, se experimenta un importante incremento del número de turistas (Barceló, 2000). Ese mismo año, aprovechando la oportunidad que ofrece la mejora de comunicaciones entre la isla y el exterior, el indiano Llorenç Roses Borràs ${ }^{3}$ y su hijo Llorenç Roses

3 Llorenç Roses Borràs (Sóller 1864 - Palma 1946), se estableció en Arecibo de la mano de sus tíos que llevaban uno de los principales empresas exportadoras de la ciudad, la casa "Roses \& Cia", que heredó cuando estos se retiraron a Mallorca. Según Marimon Riutort, Antoni (1993) en "Les repercussions de les Guerres de Cuba i Filipines a les Illes Balears". 
La "Generalitat" acaba de encargar el proyecto racionalista de la "Ciutat del Repós i Vacances", en el Delta del Llobregat, a los jóvenes impulsores del movimiento moderno y fundadores del G.A.T.C.P.A.C. ${ }^{7}$, Josep Lluis Sert, Josep Torres Clavé y Joan Baptista Subirana.

Pero en la década de 1930 Josep Goday i Casals se ha convertido en uno de los principales representantes del "noucentisme", corriente artística resultante de la evolución del modernismo, del cual su maestro Josep Puig i Cadafalch ${ }^{8}$ es uno de los principales exponentes. Desde 1910, Goday lleva a cabo diferentes intervenciones paisajísticas en la Costa Brava, como los jardines de las casas Girbau, Barquetes, de las Punxes dels Estrada en la Playa de Sant Pol de Mar, o los jardines Murtra de Blanes (1921) para el botánico alemán Karl Faust.

Desde entonces establece una sólida amistad con el arquitecto gerundense Rafael Massó, autor de una de las primeras ciudades jardín del estado, S'Agaró, también en la Costa Brava. Se trata de un proyecto que presenta un especial paralelismo con la Colonia de Artistas de Darmstadt proyectada en 1899 por Josef Maria Olbrich', una de las primeras inspiradas en los modelos de ciudad jardín británicos ${ }^{10} \mathrm{y}$ uno de los principales ejemplos urbanos del movimiento artístico de la Secesión Vienesa, el Art Nouveau austriaco, cuyo primer presidente es Gustav Klimt.

S’Agaró se convierte en uno de los principales referentes para la ciudad jardín turística mediterránea de Palmanova, aportando una clara influencia del "mediterranismo" y clasicismo compartido por el Noucentisme.

\subsection{Las lógicas de ubicación y ordenación de Palmanova}

El proyecto aprobado por el Ayuntamiento de Calvià el 3 de Octubre de 1935 consiste en una ciudad jardín de una extensión de 40,8 Ha, caracterizada por criterios de ubicación y ordenación bien propios de las primeras ciudades jardín turísticas mediterráneas.

El proyecto empieza con una buena elección del emplazamiento, basándose en tres criterios básicos: el paisaje del lugar, la accesibilidad y el imaginario vinculado al lugar.

7 GATCPAC (Grup d'Artistes i Tècnics Catalans per al Progrés i I'Arquitectura Contemporània) está proyectando diferentes modelos de "ciutats del repós i vacances" tanto en el litoral barcelonés, en Viladecans-Gavà-Castelldefelscomo en la Costa Brava, en Platja d'Aro.

8 Josep Goday i Casals (Mataró, 1882 - Barcelona, 1936), una vez licenciado por la Escuela de Arquitectura de Barcelona en 1905, es profesor ayudante de Josep Puig i Cadafalch en su cátedra de Historia del Arte. Puig i Cadafalch, tras la época de su obra denominada "blanca", con toques de influencia barroca, influencia fuertemente a Goday, hasta convertirse en autor plenamente "noucentista".

9 Según Mihail Moldoneanu en "s'Agaró, arquitectura d'un somni", Exposición desarrollada en la sede de Barcelona del Collegi Oficial d'Arquitectes de Catalunya el año 1998.

10 "Entre las primeras inspiraciones en los modelos de housing británico encontramos por un lado las Arbeiterkolonien de los Krupp en Essen, y por otro, la Künstlerkolonie realizada en Darmstadt a partir de 1901por iniciativa del gran duque Ernst Ludwin von Hessen, bajo la dirección de Joseph Maria Olbrich". Según Gravagnuolo (1.998). 


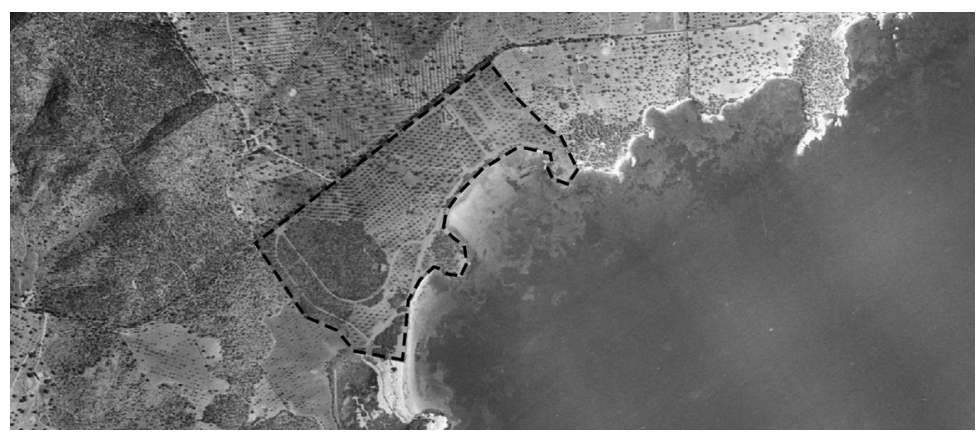

Fig. 3: Ámbito de Palmanova en el 1956. Fuente: Elaboración propia a partir del vuelo americano de 1956, SITIBSA.

Los valores paisajísticos del entorno son el principal factor que motiva la elección del emplazamiento. Las características que presenta la playa de Palmanova son excepcionales. Es el primer tramo del litoral que presenta un sistema de calas de esta dimensión, que va de Son Caliu a Magaluf. Cada playa está separada por una "Punta" o promontorio saliente al mar, una de las ubicaciones mejor valoradas por las amplias panorámicas que ofrecen de todo el entorno. En el interior, el ámbito presenta una rica diversidad paisajística, con una área agrícola de secano en la parte más plana y otra forestada sobre un montículo, donde su suave topografía garantiza vistas al mar para la mayoría de residencias unifamiliares previstas. Tal vez no sea casual el paralelismo que pueda establecerse entre la calidad paisajística de este entorno y la costa de Arecibo, en Puerto Rico.

La ciudad jardín se ubica en un lugar estratégico de máxima accesibilidad: el cruce de las carreteras Palma-Andratx-Calvià. Por un lado busca la conexión directa con la carretera Palma-Andratx, con el objeto de tener un fácil acceso a la ciudad de Palma y la principal puerta de la isla, el puerto, situado a solo $10 \mathrm{~km}$.

Además aprovecha el efecto escaparate de todos los flujos en dirección a Andratx y Peguera donde ya se han construido el hotel Platges de Peguera

Fig. 4: Ortofoto de Arecibo, Puerto Rico. Fuente: Google Earth 2013.

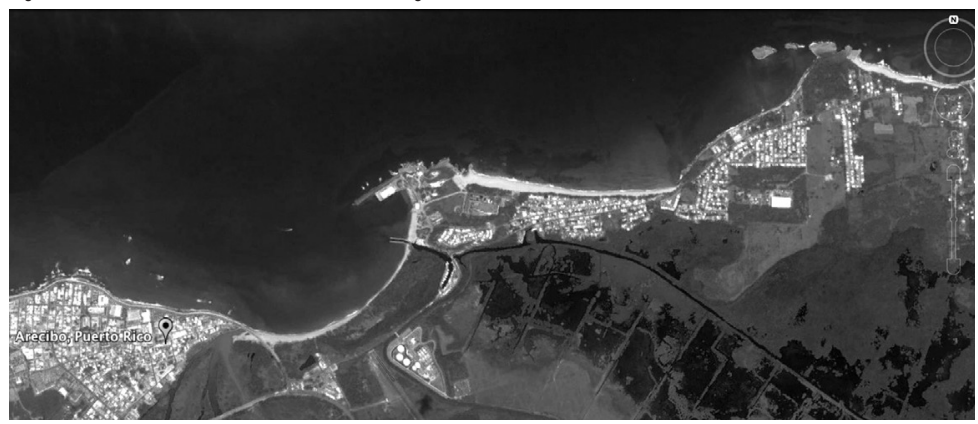




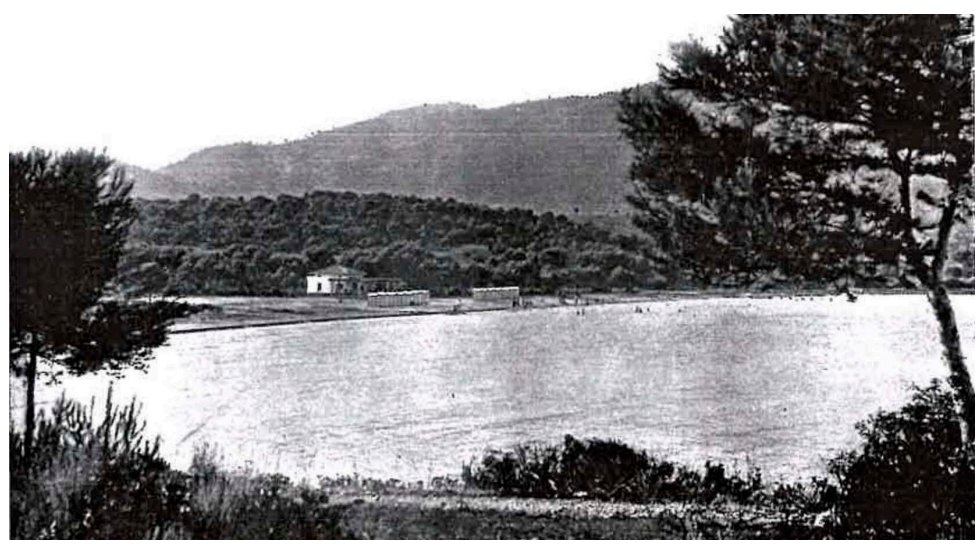

Fig. 5: Imagen de la Platja Nadala en 1935 con la pineda de la colina de Palmanova en la parte posterior. En la playa se distingue un conjunto de casas de baños existentes en el momento en que se proyecta Palmanova. Fuente: Mallorca, la isla de oro (1935), del promotor Llorenç Roses Bermejo y el arquitecto Josep Goday i Casals.

(1928) y el Malgrat (1930). Por otro lado, se trata del tramo de costa más cercano al principal núcleo del interior del municipio, el pueblo de Calvià, distante poco más de $5 \mathrm{~km}$. Las dificultades de movilidad que presenta la isla a lo largo del litoral obliga a optimizar al máximo los factores de localización.

Por otro lado, se trata de un lugar ya frecuentado habitualmente en fines de semana y temporadas de verano, llegándose a instalar casas de baños provisionales. Y es que, antes de iniciarse el proyecto de Palmanova, este fragmento del paisaje litoral ya figura en el imaginario colectivo donde pasar el tiempo libre.

Respecto a las lógicas de ordenación, el principal elemento estructurador de la ciudad jardín es el paseo marítimo. Se concibe como el espacio de mayor atracción, generando dos hitos en sus extremos, el club náutico por un lado y un área de servicios para los baños de mar, por el otro, donde los 17 metros de anchura del paseo se amplían hasta conformar una gran plaza frente al mar. Como hito central del paseo se proyecta un hotel sobre punta Marroig, con altura máxima de tres plantas y un entorno aterrazado a modo de diferentes miradores.

La nueva ciudad jardín integra una amplia diversidad de recursos turísticos. Cuenta con diferentes instalaciones deportivas, como el Club de Tenis, el Club Náutico, o el Club Marítimo con una piscina olímpica. El Parque Mirador, en la parte más elevada del conjunto, se concibe como espacio donde desarrollar los principales eventos de la temporada. Su escalinata de acceso mantiene un estrecho paralelismo con las proyectadas en los jardines Murtra de Blanes. La zona comercial y de servicios se ubica junto a los accesos al conjunto, conectando con la carretera Palma-Andratx.

En los tramos con residencias, la ciudad jardín presenta una franja de 10 metros de bosque entre la carretera y la urbanización, con el objeto de amortiguar el ruido del 


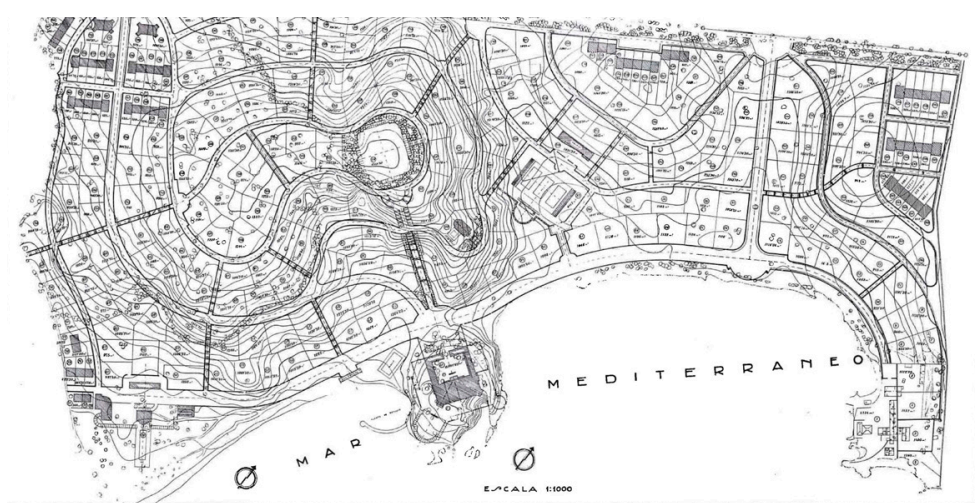

Fig. 6: Plano original de Ordenación de Palmanova. Fuente: Mallorca, la isla de oro (1935), del promotor Llorenç Roses Bermejo y el arquitecto Josep Goday i Casals.

tráfico. Desde la carretera se generan dos vías de acceso de 14 y 10 metros de ancho que llevan al principal eje vertebrador de la ciudad jardín, el paseo marítimo.

Finalmente la estructura urbana se complementa con una escuela y una iglesia. A pesar de que hoy en día dotar de una escuela a un espacio turístico pueda parecer algo singular, para Josep Goday i Casals parece no ser así. El arquitecto catalán bien seguro que es suficientemente sensible de la necesidad de dotar con equipamientos educativos a las nuevas poblaciones que colonizan el litoral. Por otro lado, si retrocedemos a los orígenes de la ciudad jardín, éstas buscan ofrecer un nueva realidad urbana para la clase trabajadora de la Europa en el creciente proceso de industralización de finales del siglo XIX y principios del XX. Es decir, crear un nuevo espacio urbano en armonía con la naturaleza y que a la vez pueda cubrir las nuevas necesidades de servicios y equipamientos para una población urbana en aumento.

Sin embargo, la singularidad de Palmanova se encuentra en su aportación en el proceso de reinvención de la ciudad jardín obrera en ciudad jardín turística mediterránea. Ésta primero se convierte en un espacio donde disfrutar del tiempo libre y de ocio, ubicándose especialmente en los puntos elevados de las periferias de las grandes ciudades, como por ejemplo el Park Güell en Barcelona de (1900-1910) o la Colonia de Artistas en Darmstadt (1899-1903). Posteriormente, después de convertirse en espacios vacacionales, experimenta un acercamiento al litoral integrando su morfología urbana al paisaje de éste, creando espacios desde donde disfrutar de las panorámicas hacia el mar, como es el camino de ronda de S’Agaró (1924-1932) o del paseo marítimo de Palmanova (1932-1935). Es así como se experimenta el proceso de transformación de un tejido urbano en ciudad jardín turística mediterránea.

En Palmanova, el trazado busca la integración a la topografía del lugar, evitando terraplenes y contrafuertes que puedan suponer un impacto excesivo. La 


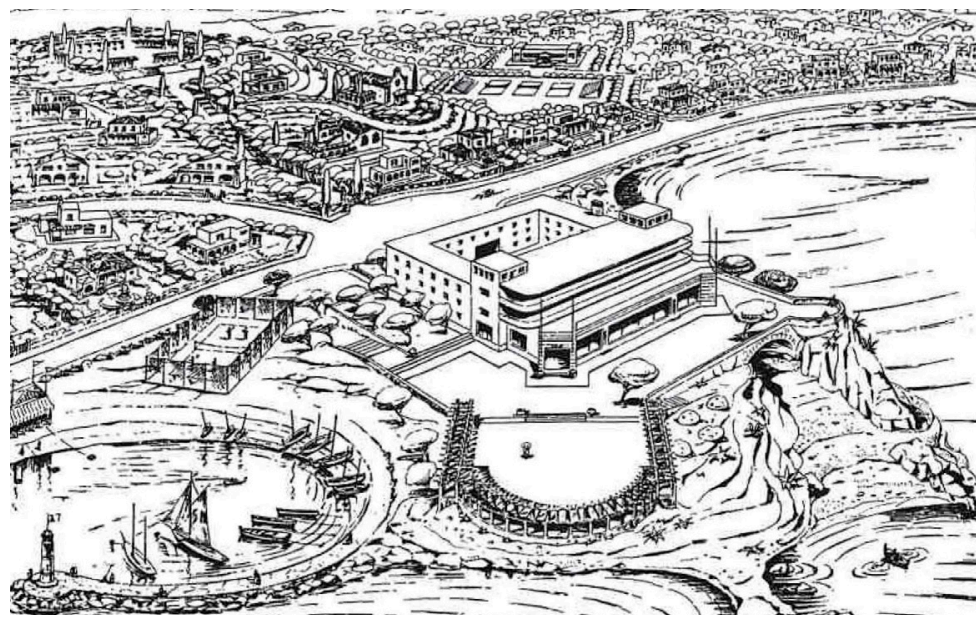

Fig. 7: Perspectiva aérea hacia el hotel propuesto, así como de las disposición de las viviendas unifamiliares y los servicios y equipamientos. Fuente: Mallorca, la isla de oro (1935), del promotor Llorenç Roses Bermejo y el arquitecto Josep Goday i Casals.

disposición de las parcelas está pensado para ofrecer las mejores panorámicas y orientación. El área residencial está conformada por calles de entre 6 y 8 metros de tráfico rodado restrigido a vecinos, cruzadas en los sentidos de máxima pendiente por senderos peatonales y escalinatas de 4 metros, que conectan los principales recursos turísticos, miradores, servicios y equipamientos.

Buscando aplicar sistemas higienistas y evitando el amontonamiento se proyectan parcelas de al menos $1.000 \mathrm{~m}^{2}$ ampliables, según el promotor, para garantizar un paisaje urbano de calidad mediante la presencia de grandes

Fig. 8: Panorámica desde la colina de Palmanova hacia Punta Nadala y Punta de Sa Porrassa. Fuente: Mallorca, la isla de oro (1935), del promotor Llorenç Roses Bermejo y el arquitecto Josep Goday i Casals.

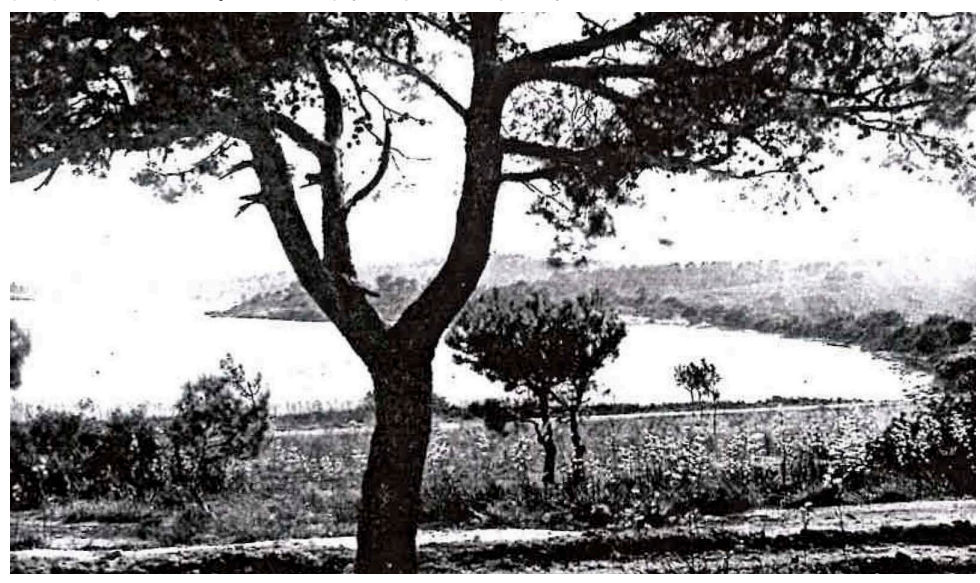




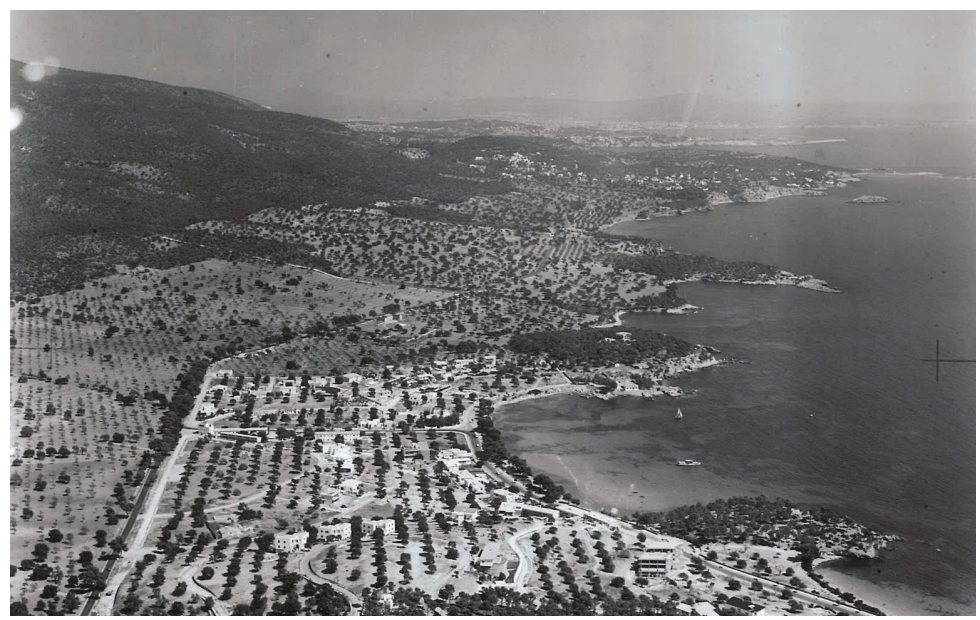

Fig. 9: La ciudad jardín turística mediterránea de Palmanova en 1960. Fuente: archivo municipal de Calvià.

jardines dentro de la trama urbana. Se proponen también casas vacacionales más económicas, en las que se adosan las edificaciones y se generan conjuntos de jardines anexos.

Además de los criterios estéticos del proyecto, se definen unos pocos parámetros a seguir: que haya tan solo una vivienda unifamiliar por solar, y que la separación a linderos y espacio público sea como mínimo de 3 metros. El resto de parámetros de las edificaciones son definidos por la Junta de Propietarios, asesorados por arquitectos.

\subsubsection{Ejecución de la ciudad jardín y ampliación hacia Torrenova}

Con el inicio de la Guerra Civil en 1936, se interrumpe la ejecución de la ciudad jardín proyectada por Josep Goday i Casals entre 1932-1935. Su promotor, Llorenç Roses Bermejo, es fusilado por su vinculación política con la República, y se confiscan los bienes a la familia. Por otro lado, dada la situación del momento, se ponen trabas al desarrollo de residencia para extranjeros, así como a la edificación en zonas costeras.

Después de más de una década, en 1947, tras un contencioso con el Gobierno, las tierras vuelven a manos de la familia Roses, y en 1951 se reemprende el proceso urbanizador de Palmanova por parte de su hijo Josep Roses Rovira.

Los parámetros urbanísticos iniciales de la ciudad jardín de Palmanova son los siguientes: 


\begin{tabular}{|l|c|c|c|c|c|c|}
\hline & $\begin{array}{c}\text { Tamaño parcela } \\
(\mathrm{m} 2)\end{array}$ & $\begin{array}{c}\text { Techo } \\
(\mathrm{m} 2)\end{array}$ & $\begin{array}{c}\text { Edificabilidad } \\
(\mathrm{m} 2 \mathrm{t} / \mathrm{m} 2 \mathrm{~s})\end{array}$ & $\begin{array}{c}\text { Altura } \\
\text { (plantas })\end{array}$ & $\begin{array}{c}\text { Ocupación } \\
\text { Edificios }\end{array}$ & Uso actual \\
\hline $\begin{array}{l}\text { Parámetros iniciales } \\
\text { de la tipología } \\
\text { ciudad jardín }\end{array}$ & $>1.000$ & 250 & 0,25 & $1-2$ & $20 \%-25 \%$ & vivienda \\
\hline
\end{tabular}

Datos fruto del interpretativo de las primeras parcelas edificadas en la ciudad jardín de Palmanova. Fuente: elaboración propia a partir de los datos de catastro http://www.sedecatastro.gob.es.

El éxito de su desarrollo es tal, que en 1953 la Banca March, que durante la Guerra Civil adquiere la finca de Sa Porrassa ${ }^{11}$, encarga al arquitecto Josep Ferragut $^{12}$ la ampliación de la ciudad jardín hacia la punta de Sa Porassa, Torrenova.

La ciudad jardín desarrollada en Torrenova, sigue aparentemente las pautas de ordenación de la original de Palmanova, de manera que el trazado de calles busca la adaptabilidad al terreno, incorporando trazas sinuosas, adaptadas a las curvas de nivel, mientras que las sendas peatonales o escalinatas resuelven las áreas de máxima pendiente. Con el objeto de garantizar un paisaje urbano de máxima calidad se amplia la parcela mínima de 1.000 a $1.500 \mathrm{~m}^{2}$ para que pueda desarrollar un espacio ajardinado de mayor extensión.

El punto más débil que presenta la nueva ordenación es la relación con el litoral. En Torrenova se produce una privatización del frente de mar, tanto en las zonas de pendiente abrupta, como en las más planas, frente a la Playa de Magaluf, dejando únicamente unos pasos peatonales de 2 metros de ancho cada 100 metros para generar un acceso puntual hasta la costa rocosa mediante largas escaleras.

\subsubsection{Proceso de transformación de Palmanova-Torrenova}

Con la reactivación de la actividad turística en la isla, muy pronto se construyen los primeros establecimientos turísticos: el hotel Playa de Palmanova (1957) y el Moroco (1959), y más tarde el Hawái (1960) en Torrenova. Pero es a partir de la apertura del nuevo aeropuerto de Son Sant Joan en 1960 y de la mejora de las comunicaciones entre éste y Calvià, especialmente tras la inauguración del Paseo Marítimo de Palma en 1962, cuando el municipio empieza a desarrollar todo un conjunto de figuras de planeamiento con el objetivo de convertirse en el principal destino de turístico de la isla.

Con el incremento de la demanda turística, José Roses Rovira lleva a cabo en 1961 una primera modificación mediante el Proyecto de Urbanización y Ampliación de Palmanova, en el que se reduce la parcela mínima de la urbanización de Palmanova a $700 \mathrm{~m}^{2}$. 


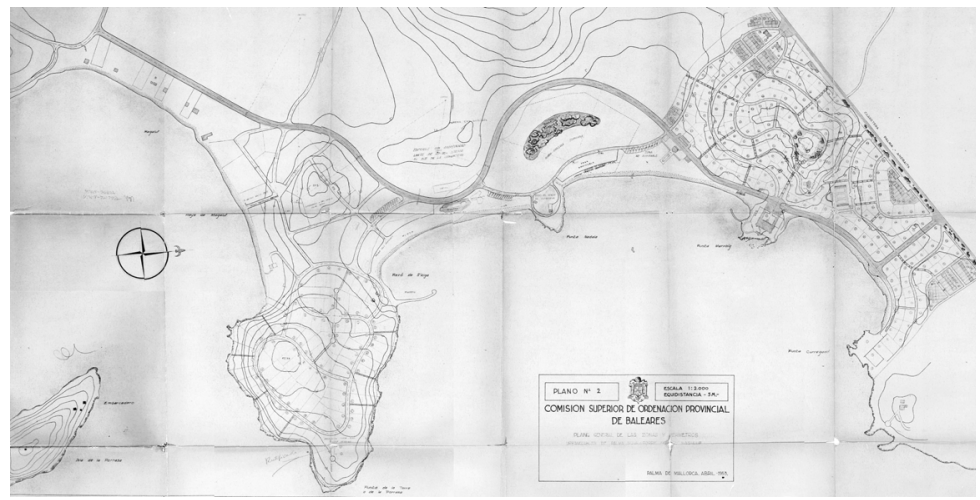

Fig.10: Plano de Ordenación de Palmanova - Torrenova de 1953. Fuente: archivo municipal de Calvià.

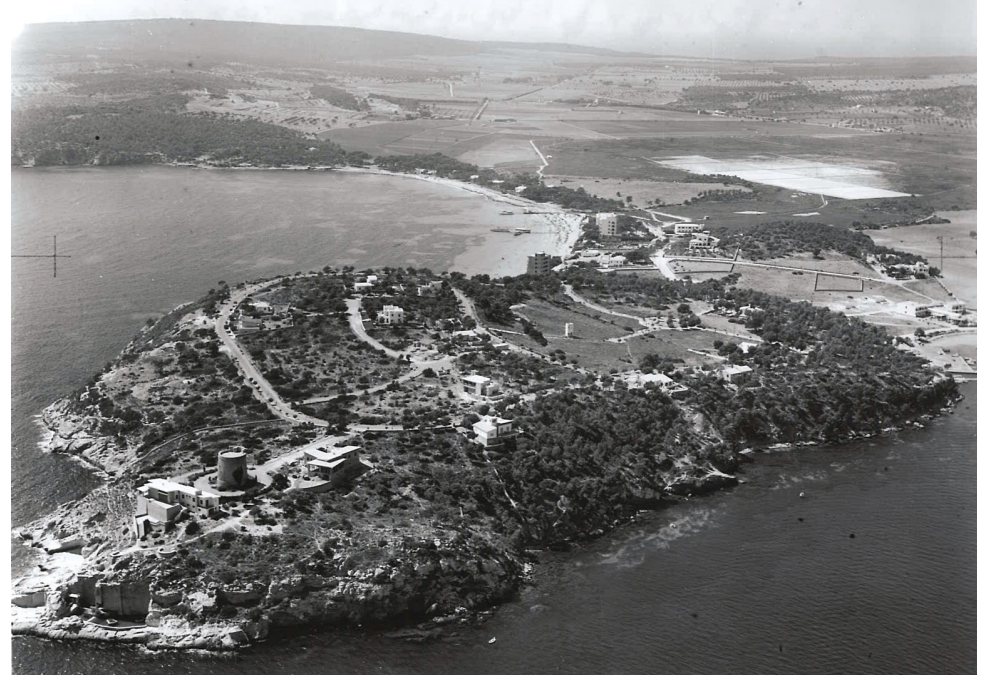

Fig. 11: La ciudad jardín de Torrenova en 1960. Fuente: archivo municipal de Calvià.

En 1962, el Plan General de Ordenación de la Costa de Calvià, extiende el tejido de ciudad jardín de Cala Blanca hasta Cala Figuera, aunque con una importante reducción del tamaño mínimo de parcela de hasta $300 \mathrm{~m}^{2}$, un incremento de la edificabilidad, y la posibilidad de incorporar nuevos usos como “...hoteles u otros de tipo similar que requieren para su explotación económica e incluso más por un afecto de composición, una mayor altura ..."13

13 Según la norma 9 del Plan General de Ordenación de la Costa de Calvià (1962). Tramo entre Cala Blanca y Cala Figuera, del arquitecto Rafael Llabrés. 


\begin{tabular}{|l|c|c|c|c|c|c|}
\hline \multicolumn{1}{|c|}{ Zona } & Tipología & $\begin{array}{c}\text { Tamaño de } \\
\text { parcela }(\mathrm{m} 2)\end{array}$ & $\begin{array}{c}\text { Techo } \\
(\mathrm{m} 2)\end{array}$ & $\begin{array}{c}\text { Altura } \\
\text { (plantas) }\end{array}$ & $\begin{array}{c}\text { Ocupación } \\
\text { Edificios }\end{array}$ & Uso actual \\
\hline $\begin{array}{l}\text { Palmanova- } \\
\text { Torrenova-Magaluf }\end{array}$ & Chalet & $>300 \mathrm{~m} 2$ & $>1.200$ & 2 & $15 \%$ & $\begin{array}{c}\text { Vivienda, } \\
\text { hotel, } \\
\text { sanitario, } \\
\text { deportivo }\end{array}$ \\
& $\begin{array}{c}\text { Bloque o torre } \\
\text { condicionado } \\
\text { a solicitud de } \\
\text { permiso. }\end{array}$ & $\begin{array}{c}y>\text { de } 15 \mathrm{~m} \\
\text { de fachada }\end{array}$ & $>400$ & $\begin{array}{c}\text { Dist. mínima } \\
\text { linderos } 3 \mathrm{~m}\end{array}$ & \\
\hline
\end{tabular}

De esta forma se empiezan a desarrollar diferentes Planes Especiales y Proyectos de Ordenación Edificatoria que permitan justificar la modificación de los parámetros genéricos del conjunto en los puntos donde el mercado turístico demanda un alojamiento diferente al de la vivienda unifamiliar.

Mediante el Plan Especial de Urbanización de Torrenova de 1.962, se experimentan los primeros cambios sustanciales. La edificabilidad que en el proyecto original es de $0,25 \mathrm{~m}^{2} \mathrm{t} / \mathrm{m}^{2} \mathrm{~s}$ pasa a $0,9 \mathrm{~m}^{2} \mathrm{t} / \mathrm{m}^{2} \mathrm{~s}$; se aumenta la superficie de ocupación en parcela, y amplia la altura máxima edificable. De las 2 plantas iniciales se pasa a 6 , sin contabilizarse las plantas que se incorporen por debajo de la cota de rasante (ver figura 12 de la ordenanza reguladora). Respecto a la relación con el mar, deja de lado cualquier posibilidad de adaptarse a las formas de este abrupto y variado litoral, para facilitar un acceso peatonal. Consecuentemente se da comienzo a la progresiva alteración de la costa de Calvià.

En 1963, se encarga el Proyecto de Ordenación Edificatoria de Punta Marroig al que en ese momento es uno de los arquitectos de referencia para las grandes corporaciones de la isla y del movimiento Moderno de Mallorca, Josep Ferragut ${ }^{14}$, que paralelamente está proyectando el edificio de GESA en el frente litoral de Palma. La nueva ordenación propuesta en Punta Marroig aumenta la altura máxima permitida de 3 a 13 plantas con un volumen total de $4 \mathrm{~m}^{3} \mathrm{t} / \mathrm{m}^{2} \mathrm{~s}\left(1,33 \mathrm{~m}^{2} \mathrm{t} / \mathrm{m}^{2} \mathrm{~s}\right)$, además de introducir también el criterio de no computar las plantas por debajo de la rasante, que ya se ha propuesto en Torrenova, aprobándose dicha ordenación en 1967.

El Plan General de Ordenación Urbana de Calvià ${ }^{15}$ de 1971 supone su consolidación como el principal municipio de turismo de masas de la isla. La ciudad jardín de Palmanova y Torrenova se define en los objetivos del PGOU como uno de los principales centros costeros:

“...se han previsto una serie de núcleos densos, basados en los asentamientos de población más antiguos (casos Portals Nous, Palmanova y Peguera), o bien de re-

14 El arquitecto Josep Ferragut Pou (1912-1968) después de participar en los Planes de Reforma de la ciudad de Palma con el urbanista Gabriel Alomar, estuvo desarrollando diferentes proyectos para la compañía eléctrica de las islas, GESA. Ese mismo año, 1967, empezaba las obras del que sería su edificio insignia en la fachada marítima de Palma, una torre de también 13 plantas.

15 Aprobado definitivamente según Orden Ministerial el 3 de Junio de 1971. 


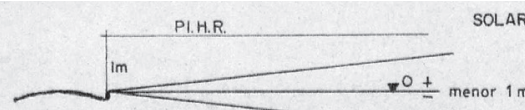

FIG.I
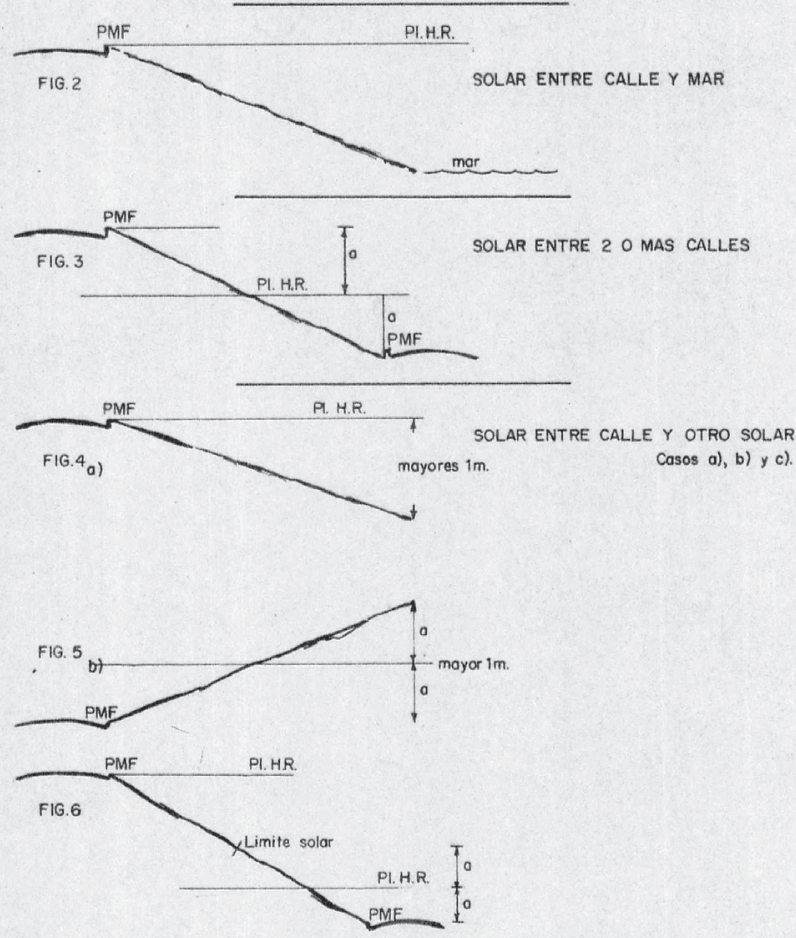

VOLUMEN QUE SE CONTABILIZA A+B

- QUe NO SE TOMA EN CUENTA CyD C. POR ENCONTRARSE POR DEBAJO DEL PI. H.R Y NO SOBREPASAR LA PROYECCION VERTICAL DEL. EDIFICIO

D. POR ESTAR SITUADA POR DEBAJO DE LAS COTAS DEL TERRENO

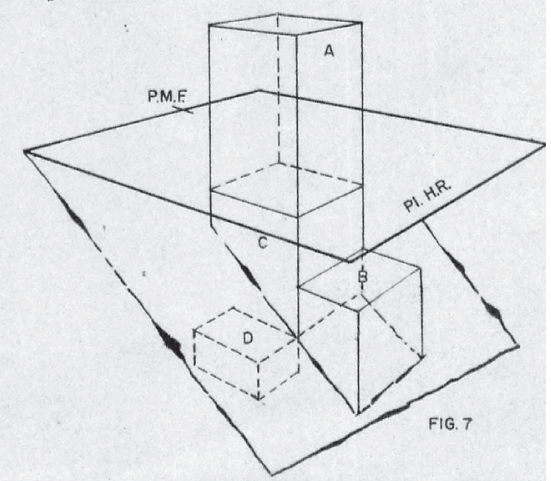

Fig. 12: Ordenanza reguladora de la altura. Fuente: Plan Especial de la Urbanización de Torrenova de 1962. 
ciente pero muy importante crecimiento (casos Magaluf, extensión de Palmanova, y Santa Ponça), ambos con topografía favorable y playas adecuadas. Estos puntos, donde se concentra el uso turístico, se prevé que sean los centros de referencia dentro del litoral turístico-residencial, tal y como puede observarse en la figura "Esquema de Nucleación Turistica" en la figura de "Esquema de Planeamiento".

Comparando este plan con el de 1953 se observan substanciales variaciones en las tipologías edificatorias. La vivienda unifamiliar consolida su parcela mínima en $400 \mathrm{~m}^{2}$, frente a los 1.500 originales; se incrementa la edificabilidad hasta un $400 \%$, pasando de 0,25 a $1 \mathrm{~m}^{2} \mathrm{t} / \mathrm{m}^{2} \mathrm{~s}$; y la superficie de ocupación aumenta en más del $150 \%$ pasando de un $25 \%$ a un $40 \%$.

Otro de los aspectos que llama la atención es como en la mayoría de ámbitos se permiten tres tipologías edificatorias, chalet, bloque y torre, manteniendo la misma edificabilidad. Consecuentemente la ciudad jardín va incorporando diferentes tipos de unidades de alojamiento turístico según la demanda del mercado, dando como resultado un tejido con una gran heterogeneidad de tipologías edificatorias.

A pesar de los parámetros definidos en las normas particulares, al aplicar las normas generales, en la mayoría de casos se acaba permitiendo una mayor edificabilidad, tal y como podemos ver por ejemplo en la Norma 13.

Fig. 13: Esquema de Planeamiento, con la definición de los principales centros costeros rodeados de las ciudades jardín turísticas. En el se puede observar como se propone que Palmanova y Magaluf sea el principal núcleo del municipio, con una capacidad de hasta 87.200 habitantes. Fuente: Plan General de Ordenación Urbana de Calvià (1971). Autor: arquitecto municipal de Calvià Vicente Bayo. Archivo municipal de Calvià.

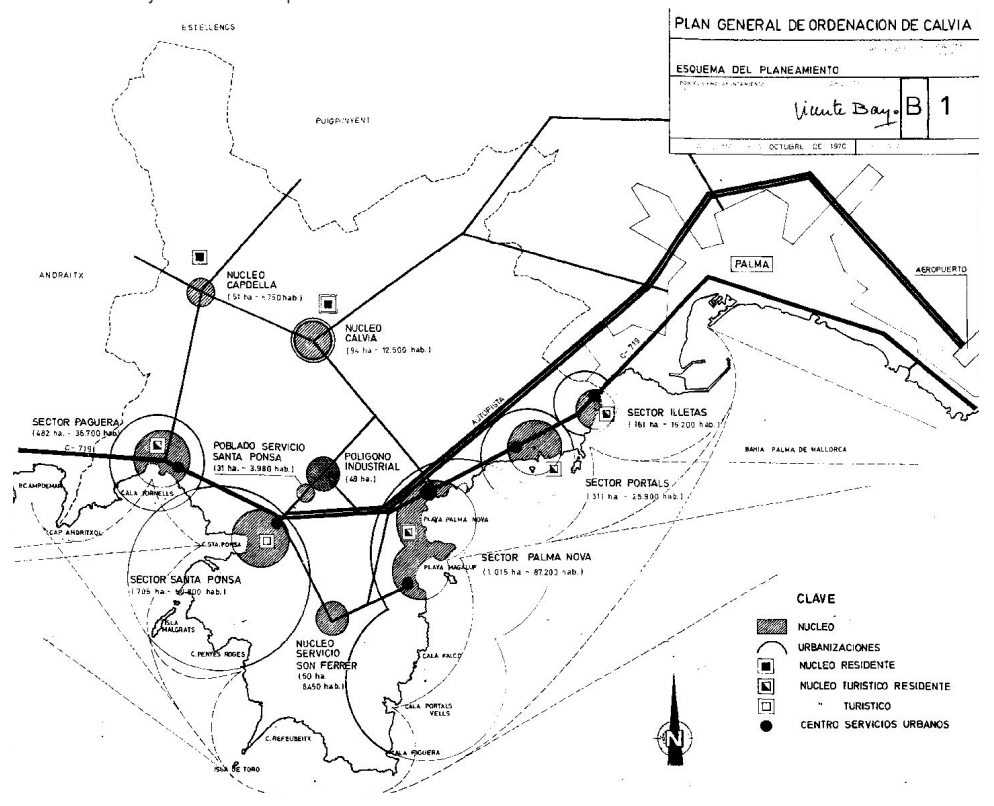




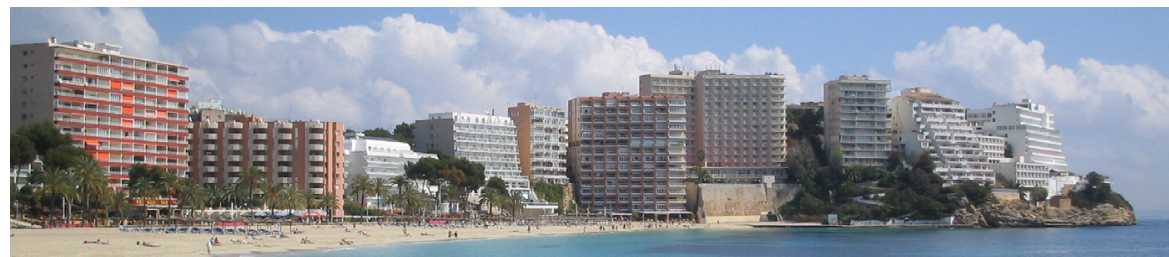

Fig. 15: Vista de la fachada marítima de la Punta de Sa Porrassa, Torrenova.

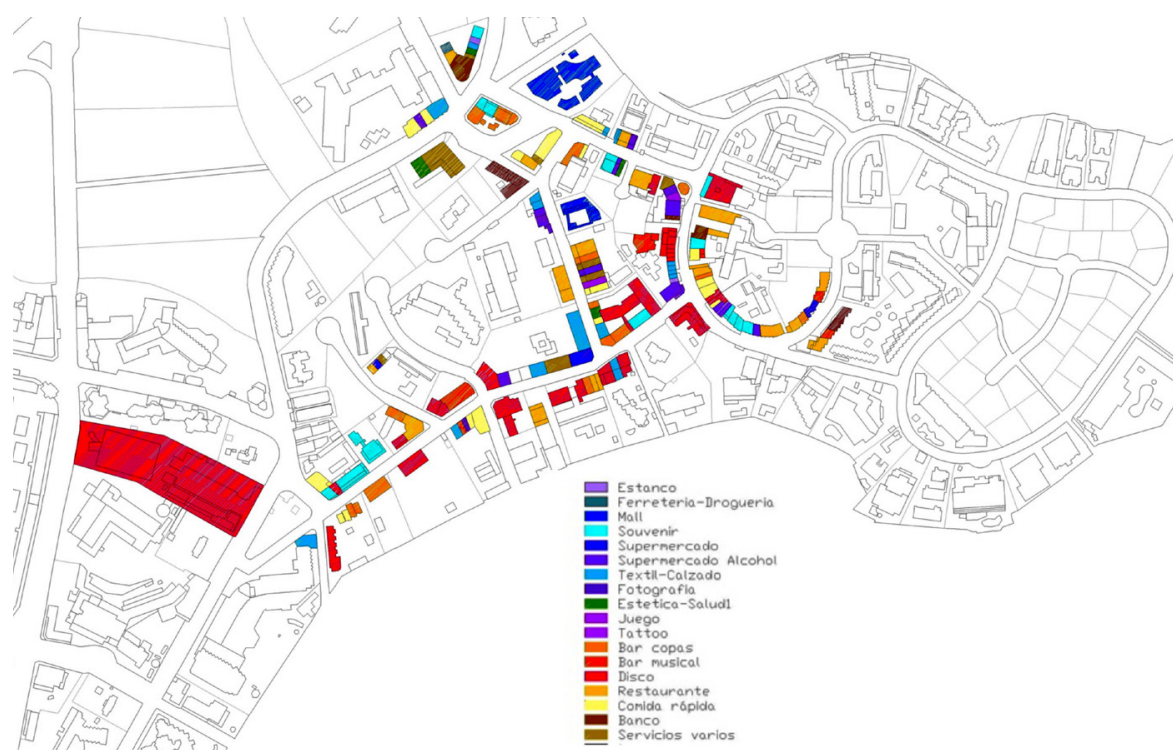

Fig. 16: Plano de usos de Torrenova, donde se puede observar la alta intensidad de actividades de ocio nocturno del sector de Punta Ballena. Fuente: elaboración propia.

Como reacción a los crecimientos en altura experimentados en los últimos 30 años en Calvià, el Plan General de Ordenación Urbana de $1991^{16}$ define una estrategia basada en la reducción de las alturas edificatorias y la extensión de las zonas turísticas mediante un desarrollo horizontal. En términos absolutos, si la adaptación del PGOU de 1982 mantiene un previsión de suelo urbano y urbanizable de 3.785 ha, el nuevo PGOU de 1991 la amplía hasta 4.037 ha. No obstante, respecto a la capacidad de alojamiento temporal se produce una reducción sustancial pasando de 340.641 habitantes (PGOU de 1982) a 229.222 (PGOU de 1991) ${ }^{17}$. Se consolida la ocupación en planta baja del 40\% que permite dotar al destino de nuevos locales para la oferta complementaria. 


\subsubsection{Palmanova-Torrenova: un tejido maduro}

La aplicación de parámetros procedentes de las diferentes figuras e instrumentos de planeamiento carentes de continuidad, y en muchos casos con lógicas de ordenación opuestas, genera una serie de dinámicas urbanas y territoriales que afectan las condiciones y el funcionamiento del espacio turístico. A estos fenómenos experimentados hay que añadir dos factores más que serán clave en el proceso de transformación de Palmanova-Torrenova en un tejido maduro, la "residencialización" y la transformación en un centro de ocio nocturno.

Buena parte del proceso de "residencialización" experimentado en el litoral de Calvià consiste en el cambio de uso de instalación turística a residencial, siendo Palmanova-Torrenova uno de los núcleos más afectados. $\mathrm{Al}$ pasar el apartamento turístico u hotel a primera residencia sin llevarse a cabo remodelaciones integrales de la edificación, aparece una oferta en el mercado de viviendas de reducidas dimensiones, dándose numerosos casos de infravivienda.

Por otro lado, tras más de 50 años de transformaciones, el sector de Torrenova presenta una alta densidad y tal grado de complejidad urbana que se convierte en un lugar atractivo para el desarrollo actividades nocturnas. Existe un importante número de residentes, que siendo también usuarios de los locales de ocio, permiten alargar la temporada de la oferta complementaria. Y finalmente, la densificación del plano horizontal ofrece una amplia oferta de locales en planta baja, sótano, semisótano, entresuelo, que permiten generar una alta intensificación de usos complementarios para desarrollar dicha actividad. El centro nocturno se concentra en la calle Punta Ballena, Torrenova, conocida como "The Strip". Su posición central y representatividad hace que su área de influencia directa abarque todo el sistema turístico-litoral de Palmanova-Magaluf. En las últimas décadas se ha convertido en uno de los centros de referencia del ocio nocturno del turismo británico. La intensidad que ha alcanzado está especializando cada vez más a todo el núcleo turístico, desplazando al turismo familiar y a residentes, en especial aquellos no vinculados laboralmente a la actividad turística.

\subsection{PROCESOS DE TRANSFORMACIÓN}

A partir del análisis realizado en el apartado anterior, identificamos los siguientes procesos o fenómenos que experimenta un espacio turístico hasta convertirse en un tejido maduro, a través de la transformación de su forma urbana: 


\section{A) Creación del destino vacacional}

Para crear un nuevo destino durante los años 30' se utiliza como referente el modelo de ciudad jardín turística mediterránea, un tipo de ordenación basado en un conjunto de baja densidad, que mantiene una cierta armonía con el paisaje litoral del momento. Este tipo de ciudad jardín confía la creación de un paisaje de calidad al espacio libre privado, de manera que sus parámetros urbanísticos permiten crear un paisaje con un mayor nivel de forestación incluso mayor que el propio paisaje pre-turístico.

\section{B) Intensificación de la ciudad jardín}

Desde principios de los años 60, con la masiva llegada de turistas, se empiezan a aplicar parámetros que permiten ampliar la capacidad de la unidad de alojamiento tipo, el chalet. Se produce la primera reducción del jardín privado pasando de parcelas de 1.000 y $1.500 \mathrm{~m}^{2}$ con ocupaciones del 15-20\%, a parcelas de entre 300 y $700 \mathrm{~m}^{2}$, con unas separaciones mínimas de la edificación a linderos de 3 metros. Dado que estas ciudades jardín apenas tienen espacios libres públicos o calles anchas que permitan arbolado, se empieza a perder la principal masa forestal que se concentra en la parcela privada.

\section{C) "Litoralización"}

Este fenómeno se genera mediante la introducción de nuevas tipologías de alojamiento que permiten acoger al turismo de masas iniciado en los años 60. Hoteles y apartamentos en altura se construyen en la primera línea de mar privando de vistas a las edificaciones de segunda y tercera fila, perdiendo así la ciudad jardín una de las cualidades que la caracterizaba. Este fenómeno genera en muchos casos no sólo una interrupción visual, sino también física cuando, por ejemplo, la nueva ciudad jardín de Torrenova no prevé ningún paso público entre las parcelas privadas y la línea de costa. Pero el mayor impacto paisajístico se produce cuando las edificaciones de estas parcelas empiezan a bajar la agreste pendiente del litoral, incrementando el número máximo de plantas por debajo de la rasante de calle, aprovechando que éstas no se contabilizan.

En la ordenación de la ciudad jardín original no se preserva ningún paso peatonal o distancia prudencial a la línea de costa, más que los 6 metros mínimos de zona marítimo-terrestre. Se confía en que este espacio de la parcela no sea ocupado por los chalets, por una cuestión de economía de medios y por tratarse de espacios con cierto desnivel, en los que se buscan los puntos más elevados que ofrezcan las mejores vistas y accesibilidad desde la calle. 
La alteración de este criterio es un buen ejemplo de las consecuencias que ha tenido la modificación de los parámetros de ordenaciones anteriores, sin entender las cualidades paisajísticas propias de los tejidos originales. Ésta es otra de las causas de degradación de los destinos turísticos maduros.

\section{D) Densificación del plano horizontal}

El planeamiento que se empieza a redactar en la segunda mitad de los ańos 80' (PGOU 1991) reduce las alturas máximas de 8, 10 y 13 a 4 y 6 plantas $^{18}$. Esta reducción viene acompañada de la aplicación de la máxima superficie de ocupación edificatoria ${ }^{19}$ permitida hasta el momento, acabando de consolidar las plantas bajas con frente a calle.

Este proceso se añade por un lado a la progresiva sustitución de las unidades de alojamiento iniciales, los chalets, y por otro a la continua adición de volúmenes complementarios a esta edificación original.

$\mathrm{Al}$ aprovechar las nuevas edificaciones la máxima ocupación permitida, generan un espacio insuficiente para el desarrollo de la pineda que caracterizaba buena parte de este litoral, experimentándose un proceso de deforestación.

Cuando estos tejidos sufren estos procesos de densificación, primero vertical y luego horizontal, se pierden las cualidades paisajísticas que ofrecía el espacio libre privado, que era el que compensaba la falta de espacio libre público en la ordenación inicial de la ciudad jardín. Mientras tanto en la nostalgia y el imaginario colectivo se deteriora la idea de Palmanova y Torrenova al ser comparada la imagen actual con aquel espacio turístico ideal, hoy desaparecido.

\section{E) Heterogeneidad edificatoria}

El proceso de continua sustitución de la tipología edificatoria original por las tipologías de alojamiento de mayor demanda según el mercado, ha generado un paisaje urbano donde predomina la heterogeneidad edificatoria, que tanto suele caracterizar los destinos maduros. Este proceso se ve intensificado durante casi 20 ańos, cuando el propio PGOU de 1971 permite dentro de una misma zona hasta 3 tipologías diferentes con la misma edificabilidad: chalet, bloque o torre en altura. Al no existir ningún tipo de ordenación previa, el resultando está en función de la tipología con mayor demanda en el mercado del momento: residencial unifamiliar, apartamentos o hotelero.

18 En el caso del litoral de Calvià PGOU no es aprobado hasta el año 1991.

19 EI PGOU de 1971 ya preveía un incremento de ocupación de parcela de hasta el 40\% para vivienda unifamiliar o edificio aislado. No obstante como también estaba permitido el bloque en altura, que mantenía la ocupación en el $30 \%$, ésta fue la tipología edificatoria predominante al dar mejor respuesta al tipo de demanda de instalación turística del momento. 


\section{G) "Residencialización”}

Los destinos maduros, durante sus casi 80 años de historia, han ido adquiriendo una mayor complejidad debido a los diferentes procesos de residencialización que han ido experimentando.

Como punto de partida el objeto de las ciudades jardín turísticas de los años 30 ' es ofrecer segundas residencias turísticas para temporadas de media y larga estancia, siendo los principales usuarios los turistas y veraneantes de la isla. Por tanto las ciudades jardín ya parten desde su propio origen de una función básicamente de residencia turística.

Desde los años 60' se experimenta el boom de desarrollo hotelero y tras la crisis de los años 70' y 90' se produce un estancamiento de la instalación turística en la isla. Los empresarios hoteleros ya no encuentran suficiente rentabilidad en la isla y reinvierten los beneficios en los nuevos destinos de tercera generación ${ }^{20}$, de manera que, buscando obtener una nueva rentabilidad del edificio, se producen todo un conjunto de bajas turísticas para transformar a las antiguas instalaciones en apartamentos de primera y segunda residencia.

El efecto del boom residencial experimentado en los últimos 15 años, se ha visto catalizado en los destinos turísticos por diversos factores. Por un lado, tras el boom hotelero desde los años 60 hasta los 80 , se inicia un proceso de regulación cada vez más estricta de la instalación turística en comparación con la laxitud del marco legal hacia el sector residencial. Durante casi tres décadas, los planes ofrecen prácticamente sólo suelo para uso residencial, de manera que los nuevos tipos alojamiento turístico en el mercado internacional, el apartamento o la vivienda turística, se ven favorecidas por la legislación local y autonómica.

De los tres procesos experimentados, seguramente el que mayor impacto ha tenido en el destino ha sido el del cambio de uso. La primera residencia se consolida a medida que el destino va perdiendo atractivo, de manera que los trabajadores de la zona turística se ven atraídos por los bajos precios y adquieren los "mini pisos" resultantes del cambio de uso de hoteles y apartamentos turísticos, que apenas han incorporado remodelaciones respecto a las instalaciones originales. Se densifica el tejido existente con población permanente, de manera que el número de habitantes en los edificios reconvertidos, llega a superar en algunos casos al número de camas de los viejos establecimientos. Se producen entonces casos de hacinamiento e infravivienda que han convertido algunas de estas zonas en focos de conflictos sociales.

20 Según Knowles y Curtis (1999) los destinos de tercera generación son aquellos desarrollados con posterioridad a los destinos turísticos del Mediterráneo Nord-Occidental y al Atlántico Sur Europeo, como serían los nuevos creados en el Caribe o en algunos puntos del Norte de África. 
En ese momento se hace patente la necesidad de que los destinos turísticos maduros den respuesta a las diferentes demandas, frente al predominio actual de la primera residencia, pero que especialmente garanticen la vivienda asequible para las clases trabajadoras, una de las causas de la degradación de muchos destinos maduros.

\section{H) Especialización en segmentos turísticos no vinculados a la calidad paisajística que diferencia el destino del resto}

“The Strip" de Torrenova ha acabado convirtiéndose en uno de los centros de ocio nocturno británico más importantes a nivel internacional, especialmente por la radicalización de las formas de ocio ${ }^{21}$. La alta densidad experimentada en estos tejidos atrae locales de ocio nocturno. Punta Ballena se encuentra ahora en su punto más álgido del turismo de excesos (sexo, drogas, alcohol y "balconing"). Tras más de 50 años de transformaciones de la ciudad jardín, se acaba reduciendo el abanico de productos experimentados en este espacio turístico hacia este tipo de turismo que expulsa al resto de segmentos, así como a los primeros residentes del entorno.

Mirando hacia atrás, podemos ver la evolución de los que habían sido los primeros destinos turísticos de la isla, y que posteriormente se convierten en centros de ocio de referencia. Es el caso de la Plaza Gomila, en el Terreno, o S'Arenal de Llucmajor, en Platja de Palma. Hoy en día estos espacios turísticos se encuentran en proceso de declive, provocado primero por el desplazamiento de diferentes segmentos turísticos, así como de los residentes, y posteriormente por el traslado de la zona de ocio a otros ámbitos. En el momento en que se produce un traslado de dichas zonas de ocio, estas tramas que han ido experimentando un proceso de transformación cada 10 años, se encuentran con un gran número de establecimientos de alojamiento, comercio y ocio turísticos sin uso, provocando la decadencia del conjunto. Dicha especialización turística pone en peligro de declive al destino, una vez estos espacios dejan de estar de moda. Por tanto, parece ser que cuando un destino está pasando por la fase de zona de ocio nocturno de uso intensivo, es un indicador de que el destino está llegando a uno de los periodos finales de su ciclo de vida.

21 Ver en documental de la BBC "The Truth about Magaluf " en http://www.bbc.co.uk/programmes/ b01pvbyy (web visitada el 23 de Octubre de 2013) 


\subsection{CONCLUSIONES}

Frente a la creencia de que los destinos maduros son fruto de la desplanificación del litoral (Knowles y Curtis, 1999; Ruzza, 2003; Moreno, 2010), en este fragmento del litoral de Calvià, hemos podido constatar cómo se ha experimentado un intensísimo proceso de planificación desde antes de la Guerra Civil. No por ello podemos descartar que la falta de un criterio unitario de planificación, especialmente a partir de la etapa del turismo de masas, afecte negativamente al ciclo de vida de los destinos turísticos (Butler, 1980).

Los destinos maduros de la isla, como es el caso de Palmanova-Torrenova, son fruto de la transformación de espacios vacacionales anteriores al inicio del turismo de masas, sometidos a intensas dinámicas territoriales generadas por la misma actividad turística. Las ciudades jardín turísticas mediterráneas originales se caracterizan por conformar un paisaje urbano respetuoso con el entorno, muy bien valorado en su momento. De manera que con la llegada del turismo de masas, la falta de inversión en nuevas infraestructuras hace que estos tejidos, que no están pensados para este tipo de turismo, incorporen instalaciones turísticas y servicios que no responden a la escala de la conformación urbana inicial.

Por otro lado, si tomamos como referencia otros casos de estudio en el ámbito internacional, observamos que la gran diferencia entre los tejidos turísticos maduros de Mallorca, y los conocidos como íntegramente planificados, como son algunos centros turísticos del Languedoc-Roussillon de los años 60-70, es que en el Sur de Francia se ejecutan proyectos fruto de una planificación continua, mientras que los casos de Mallorca son producto de una planificación discontinua, que establece criterios dispares respecto a los del planeamiento anterior. De esta forma, mientras "Candilis pasa casi 15 años dedicado al proyecto de Port Leucate-Barcarès hasta 1977, cuando es sustituido como "architecte en chef" por Michel Duplay" (Marez, 2012), el proceso de maduración de los tejidos del litoral de Mallorca se produce mediante sucesivos cambios de normativa desde la llegada del turismo de masas, adquiriendo estos tejidos una gran complejidad fruto de un continuo cambio de modelo.

El cambiante marco legal supone una evolución de su estructura y morfología urbana a través de la superposición de diferentes modelos turísticos, donde cada uno de ellos busca dar respuesta a la demanda del mercado aplicando un tipo de ordenación de acuerdo a las modas de planeamiento del momento. La fuerte atracción que generan estos tejidos mantiene en ellos siempre grandes expectativas de crecimiento. La densificación turística, residencial y de ocio de Palmanova-Torrenova presenta un nivel de intensidad proporcional a las mejoras de accesibilidad que ha experimentado Calvià (Llauger, 2006). Cuando estos tejidos llegan al límite de su capacidad para 
absorber estas instalaciones, al no ser objeto de operaciones de regeneración, han experimentado un proceso de deslocalización, primero de los residentes tradicionales, y posteriormente del turismo de perfil más cualificado y diverso, llegando así a las fases finales del ciclo de vida del destino (Butler, 1980), al final de un crecimiento que se creía que era infinito, de manera que difícilmente puede ofrecer el mismo producto turístico que el de los tejidos turísticos más recientes.

“...algunos de los primeros enclaves de origen fordista tienen, desde el punto de vista de la actividad turística, graves problemas de adaptación a la demanda posmoderna y serias debilidades de oferta postfordista. Por lo tanto, dentro del ciclo de vida turística, son destinos en declive y medioambientalmente insostenibles”. (González, 2010)

En todo este proceso de planificación del espacio turístico se dan dos situaciones bien diferentes. Por un lado, encontramos aquellos planes que buscan generar un producto turístico atractivo para la unidad de alojamiento y para el conjunto del destino. Estos planes, conscientes de que el paisaje es el principal recurso de este tipo de turismo, velan para su puesta en valor. Por otro lado, cuando se aplican ordenaciones que responden básicamente a un interés económico, intensificando las unidades de alojamiento y la oferta complementaria, no se presta suficiente atención al posible impacto sobre el entorno y sobre la calidad del producto ofertado, convirtiendo así al espacio turístico en destino maduro. 


\section{Bibliografía}

BUTLER, R. (1980). "The Concept of Tourist Area Cycle of Evolution: Implications for Management of Resources". Canadian Geographer, 24, 1, págs. 5-12

GRAVAGNUOLO, B. (1998). "Historia del urbanismo en Europa 1750-1960". Madrid : Akal ediciones.

HORRACH, B. (2009). "La Balearización. Mallorca el laboratorio internacional del turismo y su manifestación en el litoral'. Revista Iberoamericana de Urbanismo. Núm 2, http://upcommons.upc.edu/ revistes/bitstream/2099/12259/1/02_02_BielHorrach.pdf

KNOWLES, T. Y CURTIS, S. (1999). "The Market Viability of European Mass Tourist Destinations". A Post-Stagnation Life-cycle Analysis. International Journal of Tourism Research, 1 (4), págs. 87-96.

LLAUGER LLULL, M. A. (2006). "El camí de ponent. Una reflexió sobre la carretera d'Andratx i el territori'. Ed. Lleonard Muntaner, Palma.

MOLÍ FRIGOLA, M. "Cap Roig. Els jardins anglesos dels prínceps Woevodski a Catalunya”. http://dugidoc.udg.edu/bitstream/handle/10256/6633/54189.pdf?sequence $=1$

MORENO, Á. (2010). "CLIMATE CHANGE AND TOURISM Impacts and Vulnerability in Coastal Europe". Tesis doctoral por la Maastricht University. http://arno.unimaas.nl/show.cgi?fid=20143

REIXACH I PUIF, R. "Cent anys de noucentisme. Josep Goday i Casals". Ed. Capgròs Comunicació S.L.

RUZZA, C. (2003). "Environmental Sustainability and Policy Networks in Tourist Locations". En 'Policies, Governance and Innovation for Rural Areas' University of Calabria.

SEGUÍ LLINÀS, M. (1992). "El descubrimiento de las islas olvidadas. Las Baleares y Córcega vistas por los viajeros del siglo XIX”. Ed. Alpha 3, Palma.

SOCÍAS CAMACHO, J. M. (2001). "La ordenacion de las zonas turisticas litorales". Ed. Boletin Oficial del Estado.

VV.AA. (2008). "Josep Goday Casals. Arquitectura escolar a Barcelona de la Mancomunitat a la República". Albert Cubeles i Marc Cuixart (eds.) Barcelona, Ayuntamiento de Barcelona e Instituto de Educación.

BARCELO I PONS, Bartomeu (2000). "Història del turisme a Mallorca". Treballs de la Societat Catalana de Geografia, №50, 2000, págs. 31-55.

MAREZ LÓPEZ IZOL, Emilia (2012). Tesis doctoral: Movimiento moderno y los proyectos de las estaciones turísticas de Languedoc-Roussillon: La Gande-Motte y Port Leucate-Barcarès. Director: Ricard Pié. 
Biel Horrach Estarellas, Arquitecto Máster Oficial de Urbanismo Departamento de Urbanismo y Ordenación del Territorio (DUOT) Universidad Politécnica de Cataluña (UPC) bielhorrach@coaib.es 